\title{
Perceived Satisfaction With Long-Term Oxygen Delivery Devices Affects Perceived Mobility and Quality of Life of Oxygen-Dependent Individuals With COPD
}

\author{
Constance C Mussa PhD RRT-NPS, Laura Tonyan MSc RRT, Yi-Fan Chen PhD, and \\ David Vines MHS RRT FAARC
}

\begin{abstract}
BACKGROUND: Although routine physical activity for individuals with COPD is recommended, there are inherent limitations of available oxygen delivery devices that may result in hypoxemia during activity. Changes in Medicare laws have resulted in an increased use of oxygen cylinders and a reduction in the use of liquid oxygen devices. The aim of this survey was to assess the impact of perceived satisfaction with various oxygen delivery devices on perceived mobility and quality of life (QOL) of oxygen-dependent subjects with COPD. METHODS: A survey was developed to measure perceived satisfaction with current portable oxygen delivery devices, perceived mobility, and perceived QOL. The survey was deployed via a link posted on the COPD Foundation's COPD360SOCIAL social media site for 5 weeks, which resulted in the recruitment of 529 participants, of which 417 were included in the data analysis. RESULTS: Quantile regression analysis revealed that the median perceived device satisfaction score was significantly higher in the liquid oxygen device group $(P<.001)$ compared with the portable oxygen cylinder and portable oxygen concentrator (POC) groups. The median perceived mobility score was significantly higher in the liquid oxygen device group $(P<.001)$ compared with the portable oxygen cylinder group, but not the POC group. The median QOL score was significantly higher in the liquid oxygen device group $(P<.001)$ compared with the POC and portable oxygen cylinder groups. Moreover, partial leastsquares structural equation modeling regression analysis showed that perceived mobility is significantly affected by perceived satisfaction with the long-term oxygen therapy (LTOT) device (adjusted $R^{2}=0.15, P<.001$ ), and perceived $Q O L$ is significantly affected by both perceived satisfaction with the LTOT device and perceived mobility (adjusted $\mathrm{R}^{2}=0.45, P<.001$ ). CONCLUSIONS: For individuals with COPD requiring LTOT, perceived satisfaction with a portable LTOT device significantly and positively affects perceived mobility and QOL. Key words: COPD; mobility; quality of life; long-term oxygen therapy; satisfaction. [Respir Care 2018;63(1):11-19. () 2018 Daedalus Enterprises]
\end{abstract}

Introduction

Chronic lower respiratory diseases, which include primarily COPD, are the third leading cause of death in the United States and are projected to be the fourth leading

\footnotetext{
Dr Mussa and Mr Vines are affiliated with the Division of Respiratory Care, Department of Cardiopulmonary Sciences, Rush University Medical Center, College of Health Sciences, Chicago, Illinois. Ms Tonyan is affiliated with Ascension Health, All Saints Hospital, Racine, Wisconsin. Dr Chen is affiliated with the Center for Clinical and Translational Science, University of Illinois, Chicago, Illinois.
}

cause of death worldwide and seventh in morbidity burden by $20300^{1,2}$ COPD is a debilitating illness characterized by remodeling of the airways and lung parenchyma, leading

\footnotetext{
The project described was supported by the National Center for Advancing Translational Sciences, National Institutes of Health, through Grant UL1TR002003. The content is solely the responsibility of the authors and does not necessarily represent the official views of the National Institutes of Health.

Dr Mussa, Ms Tonyan, and Mr Vines presented a version of this report at AARC Congress 2016, held October 15-18, 2016, in San Antonio, TX.
} 
to persistent air-flow limitation that is not fully reversible. Many individuals with COPD experience hypoxemia of varying severity because of the air-flow limitations and the physiologic changes of the lungs. Two seminal studies and a subsequent Cochrane review have contributed to our knowledge regarding the beneficial effects of long-term

See the Related Editorial on Page 121

oxygen therapy (LTOT) in individuals with COPD. ${ }^{3-5}$ In response to these 2 studies that demonstrated a decrease in the mortality rate of individuals with COPD and severe hypoxemia, LTOT has been established as a standard of care for such individuals. However, a noteworthy criticism of these 2 pivotal studies concerns the failure of the researchers to measure impact of LTOT on the health-related quality of life (HRQOL) in the study participants. Considering that COPD is an incurable disease, improving HRQOL is an important goal in the management of individuals with COPD.

Until the 21st century, instruments used to measure HRQOL relevant to the COPD population were diseasespecific and included measures related to respiratory signs and symptoms, such as dyspnea, cough, sputum characteristics, wheezing, and chest tightness. ${ }^{6-8}$ However, because of the heterogeneity of COPD and the comorbid conditions that are often associated with it, researchers and practitioners have begun to use generic HRQOL measures in conjunction with disease-specific measures to evaluate outcomes of various interventions. ${ }^{9-12}$ For example, Engström et al ${ }^{13}$ argued that disease-specific HRQOL measures were not sufficient to examine the effect of COPD on life functions due to comorbidities frequently seen in the COPD population. In a study that assessed the HRQOL in individuals with varying severity of COPD, the researchers found that disease-specific HRQOL indicators correlated well with measures of lung function, but generic HRQOL indicators that measure emotional status and psychosocial function correlated poorly with measures of lung function. The researchers noted that because COPD is associated with multiple comorbid conditions, such as heart disease and diabetes, the comprehensive effects of COPD

\footnotetext{
Mr Vines has disclosed relationships with Aerogen, Bayer Healthcare, Boehringer Ingelheim, Carefusion, Covidien-Medtronic, Halyard, Salter Labs, and Teleflex. The other authors have disclosed no conflicts of interest.
}

Correspondence: Constance C Mussa PhD RRT-NPS, Rush University, AAC 765A, $600 \mathrm{~S}$ Paulina Street, Chicago, IL 60612. E-mail: Constance_Mussa@rush.edu.

DOI: $10.4187 /$ respcare. 05487

\section{QUICK LOOK}

\section{Current knowledge}

Oxygen therapy is a well-established standard of care for individuals with COPD and severe hypoxemia. More recently, routine physical activity has been added to the repertoire of evidence-based COPD interventions. Longterm oxygen therapy (LTOT) devices that are not portable may adversely impact the ability of oxygen-dependent individuals with COPD to engage in recommended routine physical activity and, ultimately, their quality of life. The current evidence regarding the impact of portable, lightweight LTOT devices on routine physical activity of these individuals is inconclusive.

\section{What this paper contributes to our knowledge}

A validated survey was used to assess the impact of perceived satisfaction with 3 types of LTOT devices on the perceived mobility and perceived quality of life of oxygen-dependent individuals with COPD. Analysis of survey results revealed that in oxygen-dependent individuals with $\mathrm{COPD}$, perceived satisfaction with an LTOT device affects perceived mobility. Perceived satisfaction with an LTOT device and perceived mobility were also found to affect perceived quality of life.

that are attributable to the pulmonary and non-pulmonary components are best measured with both disease-specific and generic HRQOL instruments.

The American Thoracic Society and the European Respiratory Society have jointly issued a statement regarding research priorities for improving outcomes in COPD. The statement emphasizes the importance of using outcome measures, such as quality of life (QOL), that matter to individuals with COPD (ie, outcomes that are patient-centered) to determine the effectiveness of interventions. This is because surrogate measures, including physiological variables, such as $\mathrm{FEV}_{1}$ and 6-min walk distance, as well as anatomical variables, such as imaging and histological findings, do not correlate well with patient-centered outcomes, such as dyspnea, frequency of hospitalizations, QOL, and mortality. ${ }^{14}$

There is mounting evidence that lack of physical activity contributes to COPD exacerbation, resulting in increased utilization of health-care resources. A Belgian study found that COPD subjects with a low activity level had more frequent COPD exacerbation episodes and hospitalizations than subjects with a higher activity level as measured via an accelerometer-based activity monitor for $12 \mathrm{~h} / \mathrm{d}$. The researchers also found that 6-min walk distance was lower in readmitted COPD subjects $8 \mathrm{~d}$ into their hospital stay 
than in their counterparts who stayed out of the hospital. ${ }^{15}$ A more recent study at a Veterans Affairs health-care system in the United States, in which subjects were matched on percent-of-predicted $\mathrm{FEV}_{1}$ and previous exacerbation, found that the risk for exacerbations and COPD-related hospitalizations was significantly higher for individuals with COPD who had a low activity level as compared with individuals who were more active. ${ }^{16}$ Findings from a subsequent retrospective cohort study of 6,042 subjects by Nguyen et a $\mathrm{l}^{17}$ demonstrated that self-reported moderate or vigorous physical activity of $150 \mathrm{~min} / \mathrm{week}$, as recommended, was associated with a $34 \%$ lower risk of $30-d$ readmission compared with inactive subjects (relative risk 0.66, 95\% CI 0.51-0.87).

Besides the fact that physical activity is an intervention that is currently recommended in evidence-based guidelines for individuals with COPD, the ability to engage in physical activity is an outcome measure that matters to many individuals because it is a personal goal that affects perceived QOL. However, due to inherent limitations of available oxygen delivery devices, engaging in regular physical activity may be a challenge for individuals with COPD who require LTOT to mitigate the deleterious effects of hypoxemia. A complicating issue in the United States is that changes in Medicare regulations have resulted in the replacement of liquid oxygen delivery devices with portable oxygen cylinders. The aim of this survey was to assess the impact of perceived satisfaction with various portable oxygen delivery devices on the mobility and QOL of oxygen-dependent COPD subjects.

\section{Methods}

\section{Study Design and Participants}

This cross-sectional study utilized a survey instrument that was developed to measure survey participants' satisfaction with their oxygen delivery device(s) and perceived mobility using the maximal life space component of the UAB Study of Aging Life-Space Assessment (with permission) in conjunction with self-reported walk distance (ranging from one quarter of a mile to $\geq 1$ mile) and walk frequency (ranging from none to every day of the week) to measure participant mobility. The inclusion of this well-validated and reliable scale helped to create a survey that uniquely addressed the goals of the study. ${ }^{18,19}$ The survey instrument also included a QOL scale. The survey's Likert-type QOL scale was informed by several validated QOL instruments, including the World Health Organization Physical QOL survey. The survey instrument was subsequently converted to a web-based format and hosted on REDCap, a secure, web-based application designed exclusively to support data capture for research studies. A link to the survey was distributed to potential partici- pants by posting to a social media site. The survey feature of REDCap was configured to preserve the anonymity of survey participants such that no personal identifiers, including IP addresses, were obtained. Demographic data regarding age, sex, length of COPD diagnosis, COPD severity, oxygen device use, and Medicare recipient status was collected. Study approval was obtained from our institutional review board.

\section{Data Collection}

The COPD Foundation enabled the collection of data by publishing the survey link on their COPD360SOCIAL social media site for 5 weeks. The target population consisted of oxygen-dependent subjects with COPD, the majority of whom use Medicare to pay for their oxygen supplies.

\section{Statistical Analysis}

Among 529 survey respondents, to avoid any mixture, we focused only on subjects with one single LTOT device $(n=465)$. We subsequently excluded subjects with any missing values $(n=48)$. Although $10 \%$ of the data are missing, there is no statistically significant difference in characteristics between subjects with and without missing data (not shown). Given that missing completely at random assumption may hold (i.e., missing data is independent of bias in the research process), we proceeded with the analysis using complete cases.

We evaluated the reliability and discriminant validity of the mobility, QOL, and device satisfaction scales using Cronbach's $\alpha$ and Fornell-Larcker criterion, respectively. Convergent validity was assessed by computing the average variance extracted for all of the items used to measure each construct. ${ }^{20,21}$ Convergent validity demonstrates the strength of the relationship between the different indicators used to measure the same construct and explains the average amount of variance that a construct explains in its indicator variables relative to the overall variance of its indicators. ${ }^{21}$ An average variance extracted of 0.5 or greater is considered acceptable as it indicates that the construct explains $>50 \%$ of its indicators' variance..$^{20,21}$ The composite score of each scale (mobility, QOL, and device satisfaction) of the survey instrument consists of only verified items. The composite scores for the QOL and device satisfaction scales were obtained by averaging each participant's responses to the multiple verified items on the survey instrument that measure QOL and device satisfaction, respectively. Composite scores for the mobility scale were calculated using a specific computational algorithm based on each participant's responses to the multiple verified items that measure mobility. The results of these assessments presented in Tables 1 and 2 demonstrate acceptable psychometric properties of the survey instrument. 
Table 1. Survey Reliability and Validity Assessment Summary

\begin{tabular}{|c|c|c|c|}
\hline Latent Variable & Manifest Variables & Cronbach $\alpha$ & AVE \\
\hline Mobility & $\begin{array}{l}\text { Maximal life space } \\
\text { Walk distance } \\
\text { Walk frequency }\end{array}$ & .67 & 0.60 \\
\hline Device satisfaction & $\begin{array}{l}\text { Device helpful } \\
\text { Device improved QOL }\end{array}$ & .86 & 0.88 \\
\hline QOL & $\begin{array}{l}\text { Satisfaction, health } \\
\text { Satisfaction, QOL } \\
\text { Life enjoyment } \\
\text { Life meaning } \\
\text { Life energy } \\
\text { Life ADL }\end{array}$ & .89 & 0.65 \\
\hline \multicolumn{4}{|c|}{$\begin{array}{l}\mathrm{AVE}=\text { average variance extracted } \\
\mathrm{QOL}=\text { quality of life } \\
\mathrm{ADL}=\text { activities of daily living }\end{array}$} \\
\hline
\end{tabular}

Table 2. Fornell-Larcker Criteria for Discriminant Validity

\begin{tabular}{lccc}
\hline \hline Latent Variable & Mobility & Device Satisfaction & QOL \\
\hline Mobility & $\mathbf{0 . 7 8}$ & & \\
Device Satisfaction & 0.34 & $\mathbf{0 . 9 4}$ & \\
QOL & 0.48 & 0.56 & $\mathbf{0 . 8 1}$
\end{tabular}

Boldface type indicates the square root of the average variance extracted for each construct. $\mathrm{QOL}=$ quality of life

The sample was summarized across device groups by using the frequency with the percentage for categorical variables and the median with the interquartile range for continuous variables. We assessed the distributional difference across device groups for each variable by using the chi-square test for categorical variables and the KruskalWallis test for continuous variables due to skewness of distributions. Moreover, we fitted quantile regressions on median scores to investigate the effect of the device on each concept (namely mobility, device satisfaction, and life satisfaction). The associations between concepts were also explored in a similar way. Each model adjusted for sex (female vs male), age group ( $\leq 64$ vs $>64$ ), COPD severity (mild/moderate vs severe), and Medicare indicator. These statistical analyses were conducted using SAS 9.3 (SAS Institute, Cary, North Carolina). Two-sided $P$ values $<.05$ were considered as statistically significant. We used partial least-squares structural equation modeling using Addinsoft's XLSTAT 2016 statistical software, a data analysis add-on for Excel (Microsoft, Redmond, Washington), to evaluate the relationship between device satisfaction and mobility as well as between QOL and both mobility and device satisfaction.

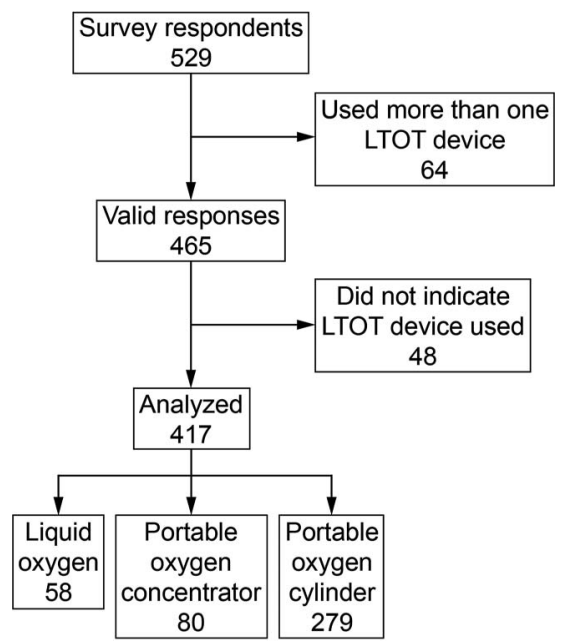

Fig. 1. Flow chart. LTOT = long-term oxygen therapy.

\section{Results}

Of the 529 survey respondents, 417 were included in the final data analysis, because 64 indicated that they used one LTOT device and 48 did not indicate the LTOT device used (Fig. 1). Table 3 shows the demographics of our analyzed sample for 417 subjects. The sample consisted of more females (81\%), Medicare users (73\%), subjects with severe COPD (80\%), and subjects who were $>64$ y old $(52 \%)$. Across device groups, the distributions were not statistically different for sex $(P=.28)$ and COPD severity $(P=.96)$, but were statistically different for age $(P=.043)$ and Medicare $(P<.001)$, since subjects in the liquid oxygen group tended to be older Medicare users than subjects in the other 2 device groups. Oxygen usage is summarized in Table 4. For our primary outcomes of interest, including perceived device satisfaction, mobility, and QOL, the trend in Table 5 was consistent, since there was a statistically significant difference in distribution across groups, and the liquid oxygen group showed higher scores than the portable oxygen concentrator (POC) and portable oxygen cylinder groups. All 3 outcomes showed statistical distributional difference in terms of $P$ values $(P<.001)$.

Results of the quantile regression analysis revealed that the median perceived device satisfaction score was significantly higher in the liquid oxygen device group $(P<.001)$ compared with the portable oxygen cylinder and POC groups. The median perceived mobility score was significantly higher in the liquid oxygen device group $(P=.02)$ compared with the portable oxygen cylinder group, but not the POC group. The median QOL score was significantly higher in the liquid oxygen device group $(P<.001)$ compared with the POC and portable oxygen cylinder groups. 
Table 3. Characteristics of Study Participants, Grouped by Long-Term Oxygen Therapy Device

\begin{tabular}{|c|c|c|c|c|c|}
\hline Characteristics & Total $(N=417)$ & $\operatorname{LOX}(n=58)$ & $\mathrm{POC}(n=80)$ & POCyl $(n=279)$ & $\begin{array}{l}P \text { for LTOT Device Groups } \\
\text { (LOX vs POC vs POCyl) }\end{array}$ \\
\hline Age & & & & & $.043 *$ \\
\hline$\leq 64 \mathrm{y}$ & $201(48)$ & $21(36)$ & $34(42)$ & $146(52)$ & \\
\hline$>64 y$ & $216(52)$ & $37(64)^{*}$ & $46(58)$ & $133(48)$ & \\
\hline COPD severity & & & & & .89 \\
\hline Mild/Moderate & $82(20)$ & $11(19)$ & $15(19)$ & $56(20)$ & .96 \\
\hline Severe & $335(80)$ & $47(81)$ & $65(81)$ & $223(80)$ & \\
\hline Medicare use & & & & & $<.001 *$ \\
\hline No & $112(27)$ & $9(16)$ & $34(43)$ & $69(25)$ & \\
\hline Yes & $305(73)$ & $49(85)^{*}$ & $46(58)$ & $210(75)$ & \\
\hline Sex & & & & & .28 \\
\hline Female & $336(81)$ & $43(74)$ & $68(85)$ & $225(81)$ & \\
\hline Male & $81(19)$ & $15(26)$ & $12(15)$ & $54(19)$ & \\
\hline \multicolumn{6}{|c|}{$\begin{array}{l}\text { Results are } n(\%) \\
\text { * Statistical significance of the observed difference in the proportion of subjects with the specific characteristic across LTOT device groups. } \\
\text { LOX = liquid oxygen device } \\
\text { POC = portable oxygen concentrator } \\
\text { POCyl = portable oxygen cylinder }\end{array}$} \\
\hline
\end{tabular}

Table 4. Portable Oxygen Usage by 417 Study Subjects

\begin{tabular}{lrr}
\hline \hline \multicolumn{1}{c}{ Parameter } & $n$ & $\%$ \\
\hline Hours of $\mathrm{O}_{2}$ use $(n=417)$ & & \\
$1-5 \mathrm{~h}$ & 10 & 2 \\
$6-12 \mathrm{~h}$ & 66 & 16 \\
$13-18 \mathrm{~h}$ & 40 & 72 \\
$19-24 \mathrm{~h}$ & 301 & 18 \\
Type of POCyl $(n=279)$ & & 48 \\
Size A cylinder/M-4 & 51 & 19 \\
Size B cylinder/M-6 & 135 & 14 \\
Size E cylinder/M-24 & 54 & \\
Other & 39 &
\end{tabular}

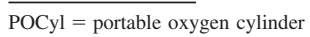

\section{Mobility's Impact on and Contribution to Device Satisfaction, and Mobility and Device Satisfaction's Impact on and Contribution to Life Satisfaction}

Results of the partial least-squares structural equation modeling regression analysis (summarized in Table 6) revealed that perceived satisfaction with an LTOT device has a significant effect on perceived mobility (adjusted $\mathrm{R}^{2}=0.15,99 \%$ CI $0.04-0.34, P<.001$ ) (Fig. 2). This finding indicates that perceived satisfaction with an LTOT device moderately $\left(f^{2}=0.17\right)$ explains $15 \%$ of the variance in perceived mobility. COPD subjects' perceived QOL was also found to be affected by both perceived satisfaction with an LTOT device and perceived mobility (adjusted $\mathrm{R}^{2}=0.45,99 \%$ CI $0.29-0.68, P<.001$ ). This finding indicates that $45 \%$ of the variance in participants' perceived QOL is strongly $\left(f^{2}=0.37\right)$ explained by perceived satisfaction with an LTOT device and moderately $\left(f^{2}=0.13\right)$ explained by perceived mobility.

\section{Discussion}

Our study findings indicate that perceived satisfaction with an LTOT device affects perceived mobility in oxygen-dependent individuals with COPD. Additionally, we found that both perceived satisfaction with an LTOT device and perceived mobility affect perceived QOL in these individuals. Although various aspects of long-term oxygen therapy have been studied extensively, very few studies have focused on the impact of oxygen delivery devices on mobility and QOL. Moreover, the few studies that address this issue have been conducted in Europe and may not be reflective of the COPD population in the United States. The scarcity of research in this area may be attributed to the reality that Medicare reimbursement for LTOT is modality-neutral, ${ }^{22}$ which means that physicians are required to prescribe an oxygen flow but not the LTOT device. Additionally, it has been noted that LTOT is usually prescribed before the patient is discharged from the hospital by acute care physicians who may not have the requisite knowledge about LTOT devices to specify the most appropriate device for the patient in the prescription. Consequently, the selection of LTOT devices has been mostly left up to the suppliers of durable medical equipment. ${ }^{22}$

In this study of oxygen-dependent individuals with COPD, liquid oxygen system use significantly and positively affected mobility and QOL, whereas cylinder use significantly and negatively affected mobility and perceived 
Table 5. Distribution of Scores for Perceived Satisfaction With Long-Term Oxygen Therapy Device, Perceived Mobility, and Perceived Quality of Life Across Type of Device Used by 417 Study Subjects

\begin{tabular}{|c|c|c|c|c|c|}
\hline Characteristics & Total $(n=417)$ & $\operatorname{LOX}(n=58)$ & POC $(n=80)$ & POCyl $(n=279)$ & $\begin{array}{c}P \text { for Distribution of Scores } \\
\text { Across Device Type }\end{array}$ \\
\hline Device satisfaction & $4.00(3.00-5.00)$ & $5.00(4.00-5.00)$ & $4.00(3.50-5.00)$ & $4.00(3.00-4.50)$ & $<.001$ \\
\hline Mobility & $9.00(6.00-11.00)$ & $9.00(8.00-15.00)$ & $9.00(7.00-13.00)$ & $8.00(6.00-11.00)$ & $<.001$ \\
\hline QOL & $3.00(2.33-3.67)$ & $3.67(2.83-4.17)$ & $3.00(2.33-3.50)$ & $2.67(2.33-3.50)$ & $<.001$ \\
\hline \multicolumn{6}{|c|}{$\begin{array}{l}\text { Results are median (interquartile range) } \\
\text { LOX = liquid oxygen device } \\
\text { POC = portable oxygen concentrator } \\
\text { POCyl = portable oxygen cylinder }\end{array}$} \\
\hline
\end{tabular}

Table 6. Effect of Predictor Variables on Perceived Quality of Life

\begin{tabular}{lccc}
\hline \hline \multicolumn{1}{c}{ Variables } & $\begin{array}{c}\text { Path } \\
\text { Coefficients }\end{array}$ & $P$ & $\begin{array}{c}f^{2} \\
\text { (Effect Size) }\end{array}$ \\
\hline Mobility & 0.29 & $<.001$ & 0.13 \\
Device satisfaction & 0.50 & $<.001$ & 0.37 \\
Age & 0.06 & .15 & 0 \\
Sex & -0.01 & .76 & 0 \\
COPD severity & -0.03 & .39 & 0 \\
Medicare & 0.03 & .53 & 0 \\
Adjusted $\mathrm{R}^{2}(\mathrm{QOL})=0.45$ & & $<.001$ & \\
& & &
\end{tabular}

The contribution of perceived satisfaction with long-term oxygen therapy device and perceived mobility to the variance $\left(\mathrm{R}^{2}\right)$ in perceived quality of life were determined using partial leastsquares structural equation modeling regression analysis. The effect size indicates how much each predictor variable in the model contributes to the $\mathrm{R}^{2}$ value of perceived quality of life. $\mathrm{QOL}=$ quality of life

QOL. Because mobility is a key determinant of satisfaction, it is understandable why oxygen devices that are perceived to increase mobility would result in a higher perceived QOL. COPD outcomes largely depend on adherence to the prescribed treatment regimen (including quitting smoking, if applicable), remaining physically active, and improving mental health. ${ }^{7,8}$ Some of the psychological hallmarks of COPD are feelings of isolation, depression, and anxiety. ${ }^{23}$ Many of these feelings may be directly related to lack of mobility due to the prescribed oxygen delivery device. If the device is too heavy, too conspicuous, too cumbersome, or too limiting and/or makes the user feel self-conscious, the patient may become withdrawn and less physically active. This in turn increases the likelihood of poor COPD symptom control and increased emergency room visits and hospitalizations. A meta-analysis of COPD health-care behavior self-management interventions ${ }^{24}$ found that physical activity improved HRQOL. The researchers postulated that physical activity contributes to less dyspnea and fatigue, with concomitant improvement in mental health and social engagement, resulting in improved HRQOL.

Based on comments from survey participants, size E cylinders are considered heavy, conspicuous, cumbersome, and limiting for many of these individuals. The following quotes from 4 of the survey participants highlight their perceived limitations to mobility imposed by portable LTOT devices:

\begin{abstract}
Absolutely hate the E tanks that represent my portable unit. They are heavy, ugly and run out of $\mathrm{O}_{2}$ within $2 \frac{1}{2} \mathrm{~h}$. My normal setting is 5 for activity. In the past, I was using a POC and then had to convert to D tanks using [a] home fill system to fill extra tanks for all trips away from home. I always encouraged COPD patients to stay active. Now, I find that I am the one that has slowed down almost to a stop.
\end{abstract}

I would be more mobile and better able to be independent if I had a more efficient portable $\mathrm{O}_{2}$ system. The tanks are heavy and take extra oxygen to even carry them. I've always maintained that if you can carry those heavy tanks you don't need $\mathrm{O}_{2}$.

The previous cylinders hinders us due to the weight. If you can't breathe, adding additional weight and [a] cumbersome device hinders a person's life that is already hindered.

The tank and shoulder bag I carry weigh 5 pounds. For some people that is not a lot, but I am a small woman who has lost a lot of strength over my years with COPD. It is bulky and hard to manage while cleaning house, working in the yard, taking care of a pet or children, etc.

It is clear from the results of this survey that this type of LTOT device may negatively affect the mobility and perceived QOL for oxygen-dependent persons with COPD. It must be noted that our survey sample consisted primarily of individuals who reported that they have severe $(80 \%)$ and moderate COPD (17\%).

Our survey results corroborate the findings of a previous Swedish study, which found that a liquid oxygen system as compared with a concentrator enhanced QOL in 


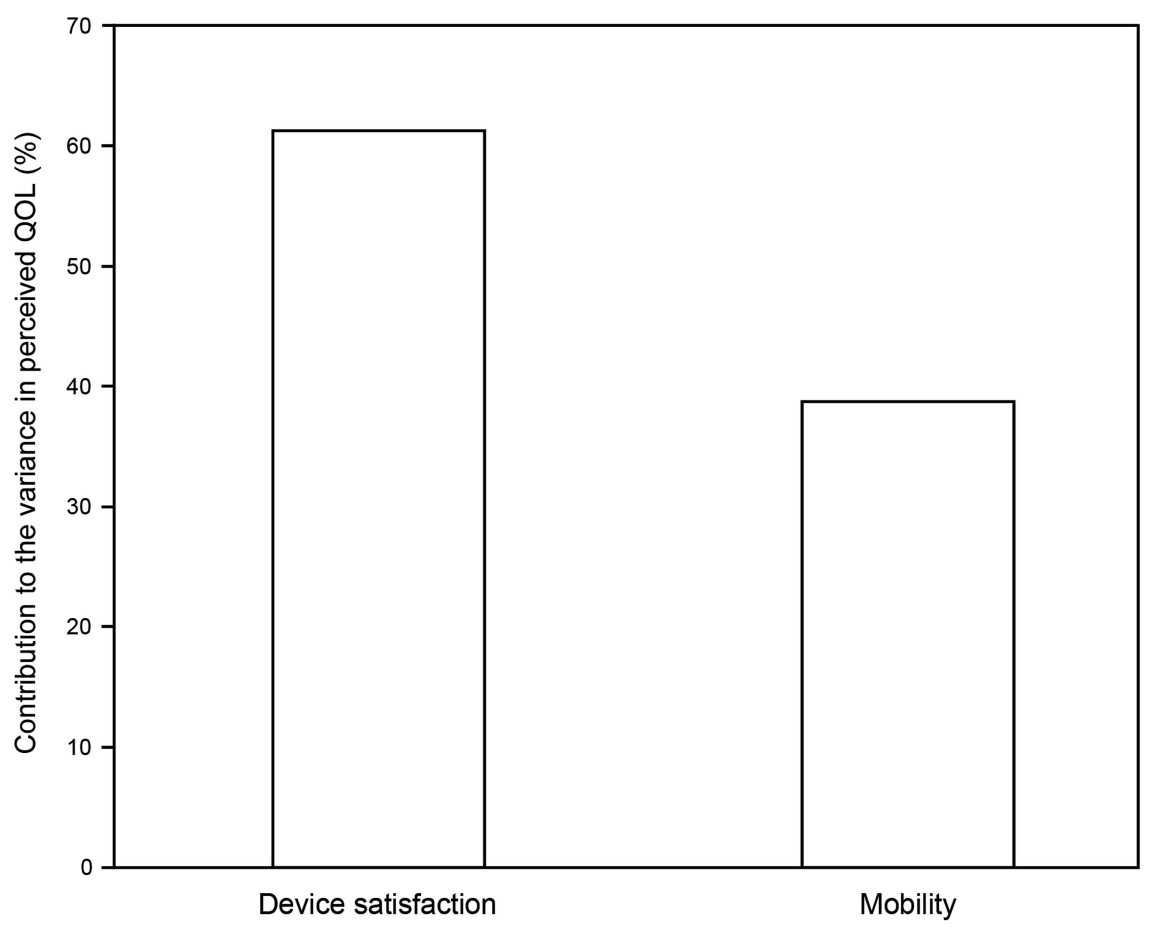

Fig. 2. Impact and contribution of device satisfaction and mobility to the variance $\left(R^{2}\right)$ in perceived quality of life based on the values of the path coefficients (partial least-squares weights), which represent the hypothesized relationships linking device satisfaction and perceived mobility to perceived quality of life in the partial least-squares structural equation model.

subjects with chronic hypoxemia as measured by the Sickness Impact Profile and the EuroQol instruments. ${ }^{25}$ The results of this study and our survey are not consistent with the findings of a study by Casaburi et al, ${ }^{26}$ in which COPD subjects with severe hypoxemia were randomized to use either E oxygen cylinders or lightweight cylinders (M-6 cylinders) weighing only 3.6 pounds. The researchers found that ambulatory oxygen use declined from baseline in COPD subjects who were given the lightweight oxygen cylinders. At the end of the study, there was no significant difference in the use of ambulatory oxygen between the 2 groups of subjects, indicating that lightweight LTOT devices did not improve mobility in those subjects. ${ }^{26} \mathrm{~A}$ significant limitation of the study by Casaburi et $\mathrm{al}^{26}$ is that it was underpowered; the authors noted that the sample size needed to detect an increase in daily oxygen use of $3 \mathrm{~h}$ in the lightweight LTOT device group was 100 participants, but only 17 participants completed the study. Additionally, the lightweight oxygen cylinder (M-6) that was used may not have been optimal for ambulation in this patient population due to fear of oxygen depletion. The authors stated that the lightweight device was set to deliver a pulse dose between 2 and $5 \mathrm{~L} / \mathrm{min}$, but this may not have been sufficient for these subjects during ambulation. Indeed, several studies have found that whereas oxygen-conserving devices meet the oxygen needs of subjects at rest, they may fail to do so during periods of activity due to various patient- and device-related factors. ${ }^{27-29}$
The results of our survey also conflict with the findings of a recent multi-center parallel group, randomized clinical trial $^{30}$ of LTOT versus no LTOT in 738 subjects with COPD and moderate resting or exercise-induced desaturation. The results of this clinical trial indicate that ambulatory oxygen does not improve the QOL, as measured with the Quality of Well-Being scale in subjects with moderate or exercise-induced desaturation. ${ }^{30}$ However, this study had several significant limitations, including the use of different LTOT devices across participants in the various study centers. Moreover, the portable oxygen device used for ambulation was not specified. Additionally, 75\% of the participants were male, which is not representative of the COPD population in the United States, where the COPD rate among women is higher than in men. ${ }^{1}$ The authors also reported significant bias in self-reported adherence to prescribed LTOT; consequently, the results of this clinical trial demonstrating no mortality benefit of LTOT should be interpreted with caution, given the complexity of COPD and the multiple factors that influence which individuals may benefit from oxygen supplementation.

Participant recruitment for our survey was achieved via an Internet-based method and is consistent with the growing trend among researchers of tapping into a more diverse population from the Internet. ${ }^{31}$ There is mounting evidence that results from research in which participants are recruited using Internet-based methods are as valid and 
reliable as results from research in which traditional means of participant recruitment are used. Casler et $\mathrm{al}^{31}$ compared results of a behavioral study from 3 different groups of participants who were recruited using the traditional method of recruiting undergraduate psychology students and using 2 Internet-based methods, namely crowdsourcing and social media. The 3 different groups of participants were asked to complete a behavioral task, which was adapted to fit an online context for the online participants. The participants who were traditional undergraduate recruits completed the task one-on-one with an experimenter in a university lab test room, ${ }^{31}$ whereas the online participants were allowed to complete the task at their leisure. The study findings demonstrated that there was no difference between the 3 groups with regard to the expected behavioral outcome. It was also noted that the online participants were more diverse than the participants recruited via the traditional method and were more representative of the general population. The researchers concluded that participants recruited online can provide valid data. Health care-related studies, including clinical trials, are also increasingly relying on online recruitment to obtain more diverse participants, decrease recruitment costs, and increase the number of participants who enroll in a study, especially for studies of rare diseases and risky health behaviors in which participant recruitment by traditional methods is challenging. ${ }^{32-34}$

Since our study relied on self-reported data, the validity of results may be compromised due to limitations inherent in this study design, such as recall bias, respondents' ability to understand the survey questions, response bias, and differences in how respondents interpret the rating scales used in the survey. The variances in mobility and device satisfaction can also be attributed to differences in personal perceptions of satisfaction among individual survey participants. Although the survey asked participants to rank levels of satisfaction with their oxygen device, QOL, and mobility, it is difficult to truly assess personal preferences. Moreover, the degree of mobility that is considered acceptable to one individual may be perceived as severely limiting to another. Additionally, because study subjects were not selected at random, there may very well be selection bias in that the portable device that was in use at the time of the study may have been influenced by the subject's mobility at baseline. Finally, because $80 \%$ of study subjects were female with severe COPD and the ability to use the Internet, the study cannot be generalized to the entire COPD population.

\section{Conclusions}

The goal of our survey was to assess the impact of perceived satisfaction with LTOT devices on the perceived mobility and QOL of oxygen-dependent individuals with
COPD. This study found that satisfaction with a portable LTOT device significantly and positively affects perceived mobility. Additionally, perceived QOL is significantly and positively affected by both perceived mobility and satisfaction with a portable LTOT device. Our findings have important implications relevant to the gap between the current evidence-based recommendation for COPD subjects to engage in routine physical activity and actual compliance, which may be attributable to the prescribed LTOT device. Future research is needed to investigate the association between various LTOT devices and physical activity, QOL, number of exacerbations, and survival in oxygen-dependent individuals with COPD.

\section{ACKNOWLEDGMENTS}

We thank Dr Patricia Sawyer (University of Alabama at Birmingham [UAB] Comprehensive Center for Healthy Aging) for allowing us access to the UAB Study of Aging Life-Space Assessment and Bill Clark for facilitating posting of the survey on the COPD360SOCIAL social media site.

\section{REFERENCES}

1. Heron M. Deaths: leading causes for 2014. Natl Vital Stat Rep 2016;65(5):1-96.

2. Mathers CD, Loncar D. Projections of global mortality and burden of disease from 2002 to 2030. PLoS Med 2006;3(11):e442.

3. Nocturnal Oxygen Therapy Trial Group. Continuous or nocturnal oxygen therapy in hypoxemic chronic obstructive lung disease: a clinical trial. Ann Intern Med 1980;93(3):391-398.

4. Long term domiciliary oxygen therapy in chronic hypoxic cor pulmonale complicating chronic bronchitis and emphysema: report of the Medical Research Council Working Party. Lancet 1981;1(8222): 681-686.

5. Crockett AJ, Moss JR, Cranston JM, Alpers JH. Domicilary oxygen for chronic obstructive pulmonary disease. Cochrane Database Syst Rev 2000;(2):CD001744.

6. Siler TM, Donald AC, O'Dell D, Church A, Fahy WA. A randomized, parallel-group study to evaluate the efficacy of umeclidinium/vilanterol 62.5/25 mug on health-related quality of life in subjects with COPD. Int J Chron Obstruct Pulmon Dis 2016;11:971979.

7. Burgel PR, Escamilla R, Perez T, Carre P, Caillaud D, Chanez P, et al. Impact of comorbidities on COPD-specific health-related quality of life. Respir Med 2013;107(2):233-241.

8. Henoch I, Strang S, Löfdahl CG, Ekberg-Jansson A. Health-related quality of life in a nationwide cohort of subjects with COPD related to other characteristics. Eur Clin Respir J 2016;3:31459.

9. Wacker ME, Hunger M, Karrasch S, Heinrich J, Peters A, Schulz H, et al. Health-related quality of life and chronic obstructive pulmonary disease in early stages: longitudinal results from the populationbased KORA cohort in a working age population. BMC Pulm Med 2014;14:134. doi: 10.1186/1471-2466-14-134.

10. Huber MB, Wacker ME, Vogelmeier CF, Leidl R. Comorbid Influences on Generic health-related quality of life in COPD: a systematic review. PLoS One 2015;10(7):e0132670.

11. Wacker ME, Jörres RA, Karch A, Koch A, Heinrich J, Karrasch S, et al. Relative impact of COPD and comorbidities on generic healthrelated quality of life: a pooled analysis of the COSYCONET patient cohort and control subjects from the KORA and SHIP studies. Respir Res 2016;17(1):81. 
12. Eaton T, Lewis C, Young P, Kennedy Y, Garrett JE, Kolbe J. Longterm oxygen therapy improves health-related quality of life. Respir Med 2004;98(4):285-293.

13. Engström CP, Persson LO, Larsson S, Sullivan M. Health-related quality of life in COPD: why both disease-specific and generic measures should be used. Eur Respir J 2001;18(1):69-76.

14. Celli BR, Decramer M, Wedzicha JA, Wilson KC, Agustí A, Criner GJ, et al. An official American Thoracic Society/European Respiratory Society statement: research questions in chronic obstructive pulmonary disease. Am J Respir Crit Care Med 2015;191(7):e4-e27.

15. Pitta F, Troosters T, Probst VS, Spruit MA, Decramer M, Gosselink R. Physical activity and hospitalization for exacerbation of COPD. Chest 2006;129(3):536-544.

16. Moy ML, Teylan M, Weston NA, Gagnon DR, Garshick E. Daily step count predicts acute exacerbations in a US cohort with COPD. PLoS One 2013;8(4):e60400.

17. Nguyen HQ, Chu L, Amy Liu IL, Lee JS, Suh D, Korotzer B, et al. Associations between physical activity and 30-day readmission risk in chronic obstructive pulmonary disease. Ann Am Thorac Soc 2014; 11(5):695-705.

18. Baker PS, Bodner EV, Allman RM. Measuring life-space mobility in community-dwelling older adults. J Am Geriatr Soc 2003;51(11): 1610-1614.

19. Peel C, Sawyer Baker P, Roth DL, Brown CJ, Brodner EV, Allman RM. Assessing mobility in older adults: the UAB Study of Aging Life-Space Assessment. Phys Ther 2005;85(10):1008-1119.

20. Henseler J, Ringle CM, Sinkovics RR. The use of partial least squares path modeling in international marketing. In: Sinkovics RR, Ghauri PN, editors. New challenges to international marketing (Advances in international marketing, Vol 20). Bingley, UK: Emerald Group Publishing Limited; 2009:277-319.

21. Henseler J, Ringle CM, Sarstedt M. A new criterion for assessing discriminant validity in variance-based structural equation modeling. J Acad Marketing Sci 2015;43:115-135.

22. Christopher KL, Porte P. Long-term oxygen therapy. Chest 2011; 139(2):430-434.

23. Jolly K, Majothi S, Sitch AJ, Heneghan NR, Riley RD, Moore DJ, et al. Self-management of health care behaviors for COPD: a systematic review and meta-analysis. Int J Chron Obstruct Pulmon Dis 2016;11:305-326.
24. Eaton T, Garrett JE, Young P, Fergusson W, Kolbe J, Rudkin S, Whyte K. Ambulatory oxygen improves quality of life of COPD patients: a randomised controlled study. Eur Respir J 2002;20(2): 306-312.

25. Andersson A, Ström K, Brodin H, Alton M, Boman G, Jakobsson P, et al. Domiciliary liquid oxygen versus concentrator treatment in chronic hypoxaemia: a cost-utility analysis. Eur Respir J 1998;12(6): 1284-1289.

26. Casaburi R, Porszasz J, Hecht A, Tiep B, Albert RK, Anthonisen $\mathrm{NR}$, et al. Influence of lightweight ambulatory oxygen on oxygen use and activity patterns of COPD subjects receiving long-term oxygen therapy. COPD 2012;9(1):3-11.

27. Bliss PL, McCoy RW, Adams AB. Characteristics of demand oxygen delivery systems: maximum output and setting recommendations. Respir Care 2004;49(2):160-165.

28. Palwai A, Skowronski M, Coreno A, Drummond C, McFadden ER,Jr. Critical comparisons of the clinical performance of oxygen-conserving devices. Am J Respir Crit Care Med 2010;181(10):1061-1071.

29. Tiep BL, Barnett J, Schiffman G, Sanchez O, Carter R. Maintaining oxygenation via demand oxygen delivery during rest and exercise. Respir Care 2002;47(8):887-892.

30. Long-Term Oxygen Treatment Trial Research Group. A randomized trial of long-term oxygen for COPD with moderate desaturation. N Engl J Med 2016;375(17):1617-1627.

31. Casler K, Bickel L, Hackett E. Separate but equal? a comparison of participants and data gathered via Amazon's MTurk, social media, and face-to-face behavioral testing. Comput Hum Behav 2013;29: 2156-2160. doi: 10.1016/j.chb.2013.05.009.

32. Close S, Smaldone A, Fennoy I, Reame N, Grey M. Using information technology and social networking for recruitment of research participants: experience from an exploratory study of pediatric Klinefelter syndrome. J Med Internet Res 2013;15(3):e48.

33. McCabe SE. Comparison of web and mail surveys in collecting illicit drug use data: a randomized experiment. J Drug Educ 2004;34(1): 61-72.

34. Yuan P, Bare MG, Johnson MO, Saberi P. Using online social media for recruitment of human immunodeficiency virus-positive participants: a cross-sectional survey. J Med Internet Res 2014;16(5):e117.

This article is approved for Continuing Respiratory Care Education credit. For information and to obtain your CRCE

(free to AARC members) visit www.rcjournal.com

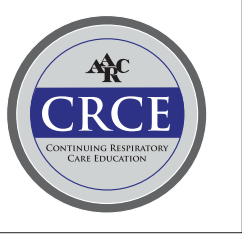

